\title{
Novel endoscopic ultrasound-guided hepaticoduodenostomy using a forward-viewing echoendoscope for altered anatomy
}

Endoscopic ultrasound-guided hepaticoduodenostomy (EUS-HDS) is used for drainage of the posterior sectoral duct (PSD) [1-5]. However, no studies have reported PSD drainage using a forwardviewing echoendoscope for surgically altered anatomy.

A 72-year-old man who had undergone pancreaticoduodenectomy with Child's reconstruction for distal bile duct cancer developed obstructive jaundice due to malignant hilar biliary obstruction caused by local recurrence (Bismuth type IIla). Two uncovered self-expandable metallic stents (UCSEMS) were deployed in the left hepatic duct and anterior sectoral duct using a partial stent-in-stent procedure via the choledochojejunostomy, but PSD drainage could not be performed. Thereafter, the patient's jaundice did not improve, so we opted for EUS-HDS for PSD drainage.

The forward-viewing echoendoscope (TGF-UC260); Olympus Medical, Tokyo, Japan) was inserted near the choledochojejunostomy ( $\mathbf{F i g . 1}$ a). The PSD was punctured with a 19-gauge needle (EZ Shot 3 Plus; Olympus Medical) from the jejunum ( Fig.1 b; Video 1), and a guidewire (M-Through; Asahi Intecc, Tokyo, Japan) inserted into B7 after cholangiographic confirmation ( $\triangleright$ Fig.1 c). Tract dilation was performed using the ES dilator (Zeon Medical, Tokyo, Japan); subsequently, a plastic stent (Through \& Pass Type IT; Gadelius Medical, Tokyo, Japan) was deployed to B7 ( $\triangleright$ Fig. 1 d).

Thirty-six days later, we reintervened to perform additional B6 drainage because of cholangitis. Cholangiography revealed stenosis of B6 and B7 separately ( Fig.2a). A guidewire (M-Through) was inserted into $B 6$, and a first stent $(8 \times$ 60 mm UCSEMS; Niti-S large cell D-type; Taewoong Medical, Seoul, South Korea) was deployed to B6 ( $\mathbf{F i g . 2} \mathbf{b}$ ). Subsequently, the guidewire was inserted into B7 through the B6 stent mesh, and a sec-
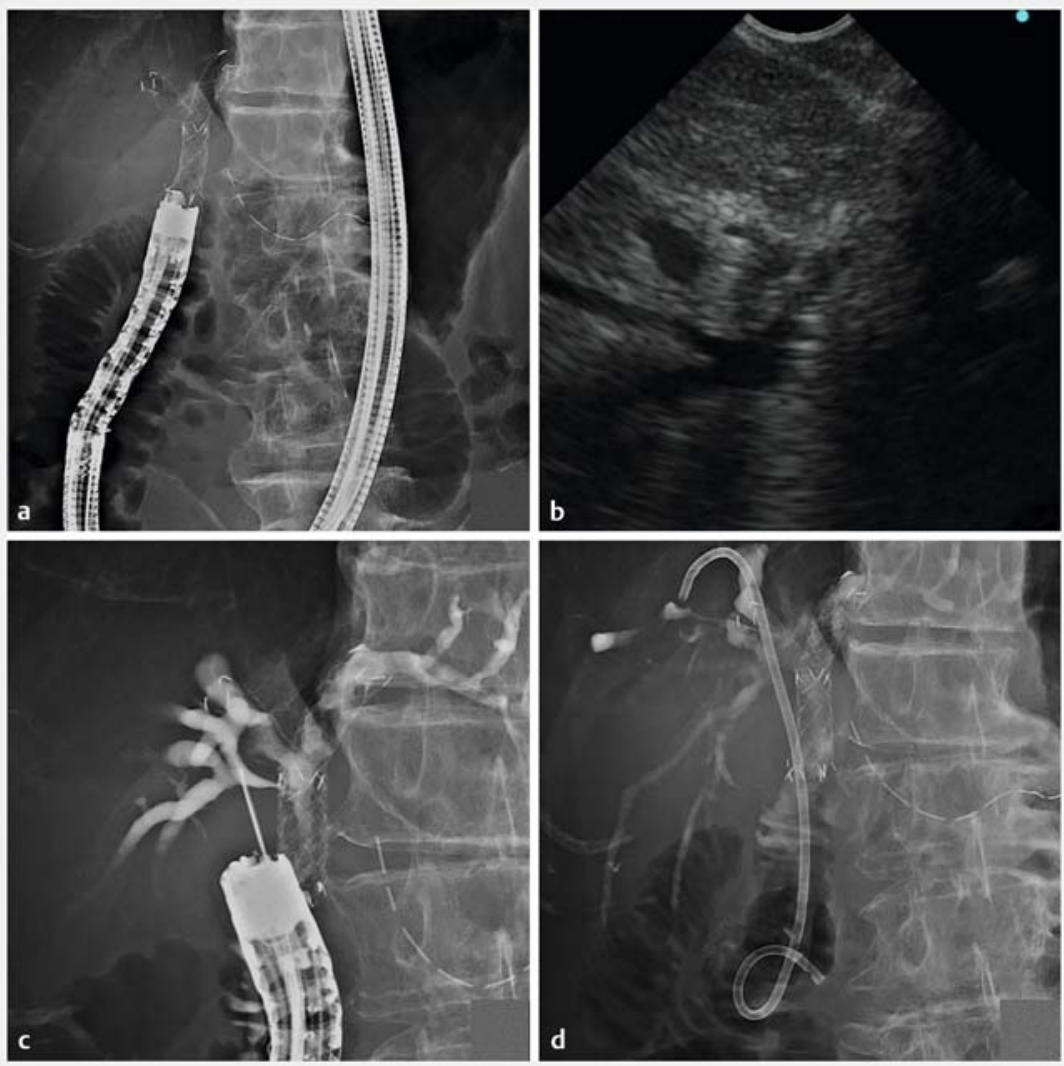

- Fig. 1 Endoscopic ultrasound-guided hepaticoduodenostomy (EUS-HDS) for drainage of the posterior sectoral duct (PSD), first session: deployment of the plastic stent from the jejunum to B7. a The forward-viewing echoendoscope was inserted near the choledochojejunostomy. b The posterior sectoral duct was punctured with a 19-gauge needle. c Cholangiography revealed dilation of the posterior sectoral duct. $\mathbf{d}$ Deployment of the plastic stent from the jejunum to B7.

ond stent $(8 \times 60 \mathrm{~mm}$ UCSEMS; Niti-S large cell D-type) was deployed to B7 using a partial stent-in-stent method ( Fig. 2c,d). Finally, we successfully deployed the metallic stent using a side-byside with double partial stent-in-stent procedure via the choledochojejunostomy and HDS fistula (> Fig.3). No adverse events occurred during the procedure, while the patient's jaundice and cholangitis improved.

Endoscopy_UCTN_Code_TTT_1AS_2AD

\section{Acknowledgement}

This work was supported in part by The National Cancer Center Research and Development Fund (31-A-13).

Competing interests

The authors declare that they have no conflict of interest. 


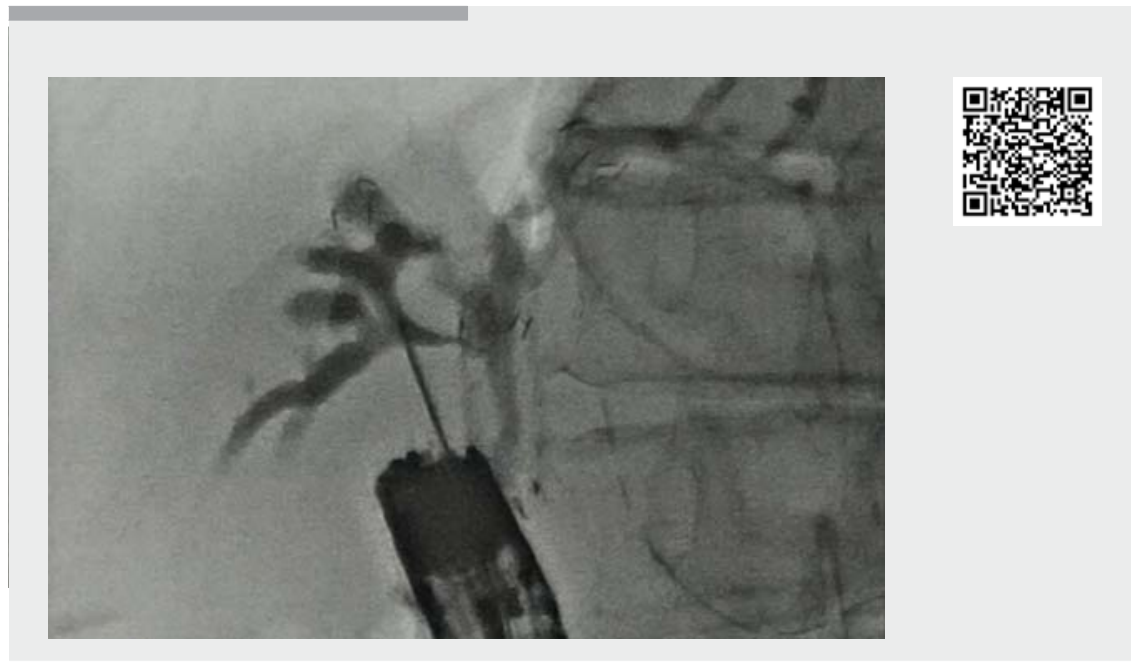

Video 1 Novel biliary drainage method for surgically altered anatomy in a patient with malignant hilar biliary obstruction, using endoscopic ultrasound-guided hepaticoduodenostomy with a side-by-side with double partial stent-in-stent method.
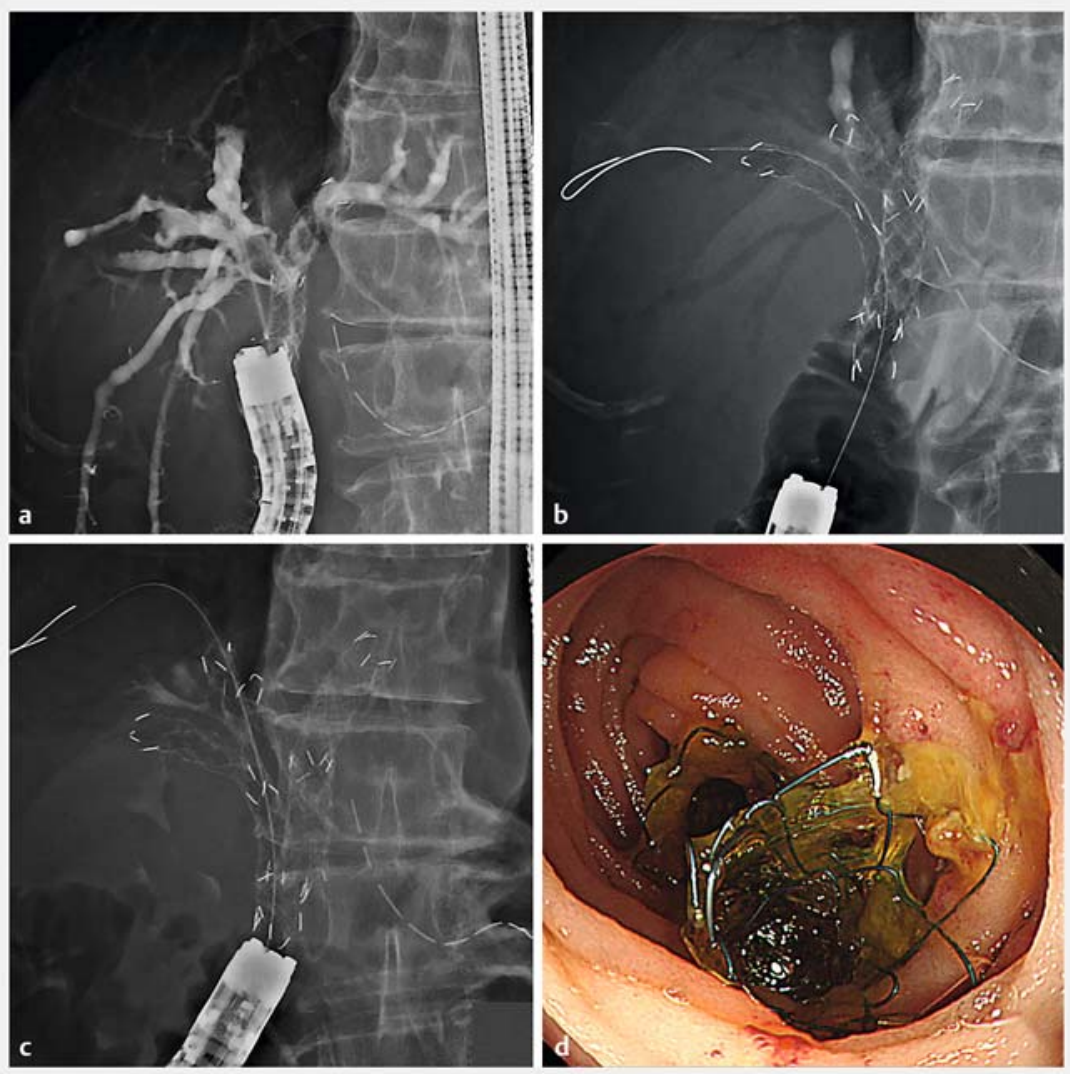

- Fig. 2 EUS-HDS for drainage of the PSD, second session: deployment of the metallic stent using a partial stent-in-stent method via the HDS fistula. a Cholangiography revealed stenosis of B6 and B7 separately. $\mathbf{b}$ Insertion and deployment of the first metallic stent from the jejunum to B6. c, $\mathbf{d}$ Insertion and deployment of the second metallic stent from the jejunum to B7 using a partial stent-in-stent method.
The authors

Yuya Hisada', Susumu Hijioka', Akihiro

Ohba', Yoshikuni Nagashio' ${ }^{1}$, Yuya Kanai ${ }^{2}$, Takuji Okusaka', Yutaka Saito ${ }^{3}$

1 Department of Hepatobiliary and Pancreatic Oncology, National Cancer Center Hospital, Tokyo, Japan

2 Department of Radiological Technology, National Cancer Center Hospital, Tokyo, Japan

3 Endoscopy Division, National Cancer Center Hospital, Tokyo, Japan

Corresponding author

\section{Susumu Hijioka, MD, PhD}

Department of Hepatobiliary and Pancreatic Oncology, National Cancer Center Hospital, 5-1-1 Tsukiji, Chuo-ku, Tokyo, Japan Fax: +81-3-3542-3815

shijioka@ncc.go.jp

\section{References}

[1] Park S], Choi JH, Park DH et al. Expanding indication: EUS-guided hepaticoduodenostomy for isolated right intrahepatic duct obstruction (with video). Gastrointest Endosc 2013; 78: 374-380

[2] Ogura T, Sano T, Onda S et al. Endoscopic ultrasound-guided biliary drainage for right hepatic bile duct obstruction: novel technical tips. Endoscopy 2015; 47: 72-75

[3] Minaga K, Takenaka M, Kitano M et al. Rescue EUS-guided intrahepatic biliary drainage for malignant hilar biliary stricture after failed transpapillary re-intervention. Surg Endosc 2017; 31: 4764-4772

[4] Hijioka S, Sakamoto Y, Ohba A et al. Novel simultaneous endoscopic ultrasound-guided hepaticoduodenostomy and hepaticogastrostomy for recurrent hepatic hilar obstruction. Endoscopy 2018; 50: E320-E322

[5] Kongkam P, Tasneem AA, Rerknimitr R. Combination of endoscopic retrograde cholangiopancreatography and endoscopic ultrasonography-guided biliary drainage in malignant hilar biliary obstruction. Dig Endosc 2019; 31: 50-54 

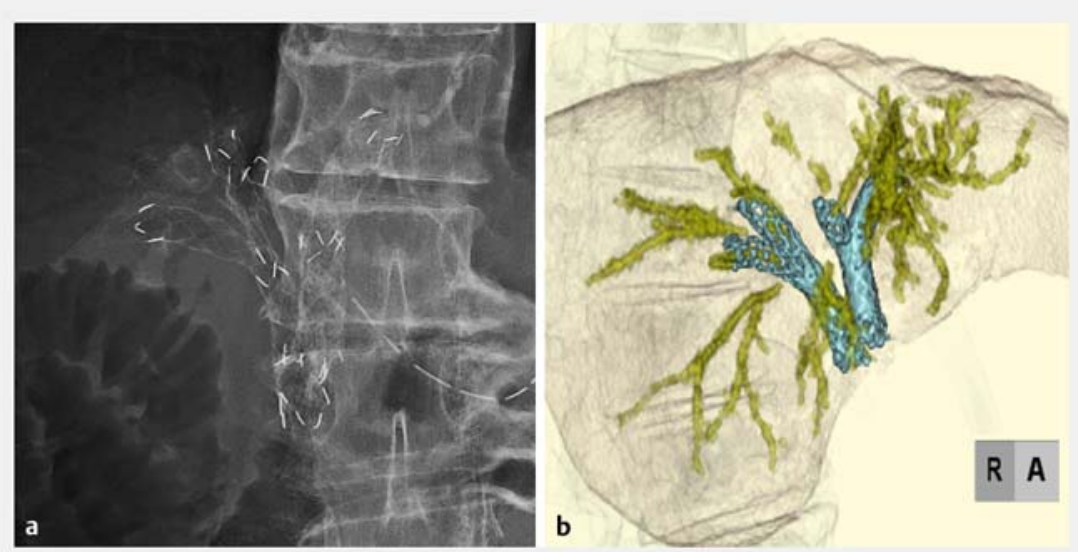

Fig.3 Deployment of the metallic stent using a side-by-side with double partial stent-instent method via the choledochojejunostomy and HDS fistula. a Fluoroscopic view. b 3D reconstruction.

\section{Bibliography}

Endoscopy 2021; 53: E340-E342

DOI 10.1055/a-1290-6561

ISSN 0013-726X

published online 11.11 .2020

(c) 2020. Thieme. All rights reserved.

Georg Thieme Verlag KG, Rüdigerstraße 14,

70469 Stuttgart, Germany

\section{ENDOSCOPY E-VIDEOS \\ https:/|eref.thieme.de/e-videos}

口回 Endoscopy E-Videos is a free access online section, reporting 自梠: on interesting cases and new techniques in gastroenterological endoscopy. All papers include a high quality video and all contributions are freely accessible online.

This section has its own submission website at

https://mc.manuscriptcentral.com/e-videos 